\title{
A ESPACIALIZAÇÃO DA FALA NO CINEMA
}

Wilcon Pereira *

TRANS/FORM/AÇAO/24

PEREIRA, W. - A espacialização da fala no cinema. Trans/Form/Ação, São Paulo, $3: 91-103,1980$.

RESUMO: O artigo parte de uma simples constatação: é bastante insatisfatória, no presente estágio da pesquisa, a colocação do problema das relações entre imagens e palavras no universo fílmico. Trata-se, no entanto, de uma questão decisiva para a estética do cinema. Em geral, as análises feitas valorizam apenas a função das imagens na gênese e no desenvolvimento das significações. A hipótese de trabalho que se apresenta aqui, vem propor, ao contrário, uma abordagem do complexo sígnico constituído pela fusão indissolúvel dos dois recursos expressivos, que forma assim um meio de comunicação específico, original e absolutamente novo. Esse caráter inédito exige uma investigação minuciosa e urgente, conjugando-se perspectivas filosóficas, semióticas e propriamente cinematográficas.

UNITERMOS: estética, semiótica, cinema, filme, fala, discurso, iconização, imaginação e logo.icônico.

Indubitavelmente, ainda não se sabe ouvir e ver um filme

\section{Jean-Luc-Godard}

1. Um desafio à estética do cinema. Situemo-nos logo de início no cerne do problema que desejamos colocar: o do estatuto da mensagem lingüística no interior de um filme. Circunscrevamos um pouco mais: qual o seu papel no âmbito de um filme narrativo e de ficção, como um dos inúmeros processos fílmico-narrativos de emprego normal no cinema contemporâneo. Qual a função do discurso falado? Mantém ainda um coeficiente de autonomia ou perde integralmente a sua especificidade? No caso de prevalecer a última hipótese, como se daria então a passagem do elemento verbal para a dimensão fílmica?

Trata-se, sem dúvida, de uma questão decisiva para a embrionária teoria do cinema, ligada em parte ao "crucial problema da relação entre imagem e palavra" ao qual se referiu com muita propriedade Galvano Della Volpe, em texto de 1967, lido na Mostra do Cinema Novo de Pesaro (20, v. 6, p. 489 a 497). Mas em lugar de palavra, que nos parece um tanto ambíguo, estabilizaremos de preferência nesta exposição o termo fala, no sentido particular e preciso que lhe é atribuído pelos lingüístas:

* Professor Assistente Doutor junto ao Departamento de Filosofia da Faculdade de Educação, Filosofia, Ciências Sociais e da Documentação da UNESP - Campus de Marília. 
PEREIRA, W. - A espacialização da fala no cinema. Trans/Form/Ação, São Paulo, 3 :91-103, 1980.

"Fala - atividade lingüística no discurso oral. E a fonação enriquecida de uma significação imanente" (4, p. 151)

"Fonação - o ato humano de emitir sons vocais. A fonação considerada em seu intento significativo, a serviço da comunicação, passa a ser fala" (4, p. 156).

Isto posto, analisaremos aqui em primeira instância os enunciados orais, a voz humana nos filmes, esses fragmentos das "linguagens humanas naturais" (15, p. 69), sintagmas em francês ou em português, em inglês ou em italiano, unidades de natureza infinitamente vária, seja sob o prisma da extensão ou da complexidade, da entonação ou da clareza na articulação. Lembremos só alguns exemplos de processos usados com bastante frequiência, inclusive nas produções comerciais: diálogos, monólogos, voz situada fora do campo visual, longas exposições ou depoimentos, sussurros, primeiros planos sonoros, assincronismos, exclamações. Enfim, toda uma gama de possibilidades que correspondem, grosso modo, a um espaço de "significações imanentes" que vai da simples interjeição às modulações do canto.

Entre esses pontos extremos, no entanto, há sempre um denominador comum. Foram vozes recolhidas, tratadas, selecionadas, alteradas, deformadas e às vezes até mesmo tornadas irreconhecíveis devido à intervenção dos recursos mecânicos, dos aparelhos que gravam e depois reproduzem os dados fônicos em condições artificiais.

2. Rápida incursão histórica. Remontemos um pouco à fase de introdução desses mecanismos, aos primórdios do assim chamado cinema sonoro. Na segunda metade da década de vinte, os engenheiros da Western Eletric põem em condição de uso os aparelhamentos necessários aos talkies. A Warner Brothers, por seu lado, atravessava uma crise econômica profunda e somente uma jogada de muito sucesso poderia salvá-la. Fruto dessa conjunção, useira e vezeira no capitalismo, a sétima arte descobre quase em tempo relâmpago a possibilidade efetiva de começar a explorar mais esta dimensão. As etapas vão sendo queimadas com rapidez, da sonorização parcial em 1926 à integração já razoável de signos visuais e auditivos no primeiro grande sucesso público: a 27 de outubro de 1927 Al Jolson extasia as platéias em Cantor de Jazz, dirigido por Alan Crosland.

Para bem caracterizar a reação de maravilhamento diante do fonofilme, nada mais expressivo do que as palavras de um grande mestre do cinema mudo. "Eu desejo as boas vindas ao cinema falado", proclamou David Griffith, "porque ele traz ao silencioso a magia da voz humana e todos os ruidos da natureza, os mais ínfimos e os mais majestosos, desde o canto dos pássaros até o estrondo do Niágara" (Apud. 9, p. 13).

A manipulação da voz humana, de sua magia, era efetivamente um sonho que fora acalentado durante algumas décadas. Mais ainda: como procurou demonstrar André Bazin, na verdade o mudo tinha sido apenas um cinema "privado de som". Por antecipação, nos seus projetos e ousadas aspirações, todos os pioneiros agiram também como profetas. Um mito diretor guiara-os nas mais diversas oportunidades e vicissitudes, a esperança de uma "imitação integral da realidade". Assim, o primado ou exclusivismo da imagem (sempre de acordo com o ensaísta francês), não passara jamais de um mero acidente, tanto do ponto de vista histórico quanto do técnico, uma vez que a imaginação dos homens do métier iden- 
PEREIRA, W. - A espacialização da fala no cinema. Trans/Form/Ação, São Paulo, 3:91-103, 1980.

tificara sempre "a idéia cinematográfica a uma representação total e integral da realidade", concebendo em todas as oportunidades "a restituição perfeita do mundo exterior, com o som, a cor e o relevo" (2, p. 24).

O certo e o definitivo, porém, o dado histórico concreto, era a apressada substituição de uma estrutura fílmica por outra, de funcionamento ainda não domesticado plenamente. Por trinta anos o fascínio do cinema havia girado sobretudo em volta da fotogenia; quase de repente, agora a beleza da imagem já não bastava, a fotogenia e a fonogenia passavam a reinar juntas. $\mathrm{O}$ realizador dirigia o olhar, teorizara Bela Balázs; pois bem, o realizador podia finalmente dirigir tanto o olhar quanto a audição. Mas para que se obtivesse um simples realismo médio, de boa qualidade, natural e verossímil, muitas dificuldades precisariam ainda ser enfrentadas com um misto de paciência e genialidade.

Recordemo-nos de alguns casos-limite, desafios extremos para os atores, diretores, produtores e técnicos desses primeiros momentos heróicos. Por exemplo, o lento aprendizado de que os sons também precisavam ser escolhidos com rigor e parcimônia, para que se tornassem realmente significativos. Ou a necessidade de uma articulação precisa entre a emissão da fala e a ação visual, a fim de evitar excessivas redundâncias, retardamentos ou mesmo fatais descompassos. Ou o perigo de uma solução de facilidade: a imitação conformista dos esquemas teatrais, das fórmulas que já se haviam mostrado fecundas no domínio cênico, mas que sem dúvida liquidariam a médio prazo a automonia e a especificidade do cinema (reveladas com êxi- to em obras-primas como Intolerância, O Encouraçado Potemkin, $O$ Ultimo Homem e tantas outras).

Tudo isso faz com que se justifique nossa admiração pelos "integrados", humildes artesãos que, nesses tempos de relações polêmicas e conflitivas com a matéria sonora, puseram-se a trabalhar e a inventar novos procedimentos de ajuste e interconexão. A fé e a competência desses artíficies ajudaram a mostrar o equívoco fatal dos "apocalípticos" (para continuar usando as categorias de Umberto Eco), que por um motivo ou outro se limitaram, de saída e por princípio, a recusar aquela que reputavam uma combinatória absurda, esdrúxula, inestética.

Mas deve-se enfatizar, sobretudo, como estão descompromissados com estas posições estreitas e unilaterais - o empirismo e a hostilidade - os grandes mestres soviéticos da época. $O$ som, anteviam lucidamente Eisenstein e Pudovkin em 1928, introduzia com efeitos singulares e preciosos meios de expressão, ampliando de muito as virtualidades do método cinematográfico. Não deveria, porém, ser transportado passivamente para o universo do filme paupérrimo caminho que acabaria por desembocar num insulso naturalismo. Ao contrário, precisaria obrigatoriamente ser cuidado pelos recursos propriamente cinematográficos, principalmente pela montagem, que continuaria o "meio fundamental (e único) para a eficácia do filme" *. Em outras palavras, tratava-se de liberá-lo plenamente da eventual fonte sonora, levando-o então a passar por múltiplas e complexas transformações. Somente com tais procedimentos técnico-artísticos se acharia em condições de entrar nos arranjos com as fotografias em movimento, o que

* Cf. a respeito o famoso manifesto de agosto de 1928, assinado por Eisenstein, Pudovkin e Alexandrov. Há uma boa tradução para o português em 6, p. 41-45. 
daria nascimento inclusive aos mais insólitos e expressivos contrapontos, assincro. nismos e fusões audiovisuais.

Critérios que nos devolvem assim ao exame do caráter especialíssimo da substância sonora agenciada pelo filme narrativo. A fala, para continuarmos limitados a este elemento, somente ingressa no circuito comunicacional já devidamente reelaborada e metamorfoseada. Sua naturalidade, espontaneidade ou imediaticidade foram de longe ultrapassadas.

3. Complexidade da faixa sonora. Abordemos agora por um outro flanco esse mesmo problema essencial, a decantação da fala no interior da obra fílmica. Para isso, examinemos um pouco o intricado amálgama de elementos que perfazem a chamada faixa de som fala, música, canções, ruídos naturais ou mecânicos, e assim por diante. A adição do campo sonoro representou, aliás, a inserção de pelo menos três séries distintas de meios expressivos, tornando muito mais complicada uma arte que vinha operando de modo relativamente simples.

"O filme mudo", notaram Stephenson e Debrix, "era uma forma comparativamente pura e homogênea. O domínio do som possui uma multiplicidade de qualidades que o da visão não possui. Não existem qualidades diferentes da imagem como as há do som - música, fala e ruídos" (18, p. 174).

De resto, acrescentaríamos nós, a própria fala, se tomada em si mesma, já é uma substância de notável complexidade intrínseca. Da sílaba ao ritmo de emissão da frase, do significado transmitido à ênfase na expressividade da voz, do longo discurso pacifista que encerra $O$ Grande Ditador de Chaplin às interjeições que representam os vários sons do amor em Julieta dos Espíritos de Fellini, de um extremo ao outro desta escala todo um conjunto de potencialidades estéticas se oferece à criatividade do cineasta.

Paradoxalmente, no entanto, apesar da utilização hoje cursiva do que Balázs intitulou "a dramaturgia do som" *, essas tão ricas e eficientes combinatórias quase não foram estudadas pelos teóricos do filme. Ou, para nuançar tal afirmação, digamos que foram tematizadas sempre de forma genérica e superficial. A música acabou por merecer alguma atenção especial, em geral breves capítulos nos manuais e tratados, contendo explicações acerca das suas influências sobre a narrativa e dos seus nexos com a atmosfera do universo figurado pelos ícones. $O$ ruído parece ter sido menos investigado, contando apenas com referências esparsas e ligeiras. Mesmo sobre a fala, de longe a mais privilegiada, tudo está ainda por ser examinado em profundidade. $\mathrm{O}$ próprio registro e alteração dela por meio de sofisticadas aparelhagens acha-se, no presente estágio da reflexão, bastante no encoberto. O que, sem dúvida, é um absurdo que nos surpreende muito desagradavelmente.

Ainda sobre o emprego da fala e as lacunas do seu enfoque teórico: foi tão. somente a forma dialogada que suscitou alguns especiais interesses. Inclusive no concernente a este setor, porém, não se pode deixar de fazer um outro reparo. As pesquisas basearam-se, em quase todos os casos, numa falácia, numa falha primordial: extrair o diálogo do contexto fíl-

* Sobre as posições dos primeiros grandes teóricos (Balázs, Armheim, Pudovkin, Eisenstein e outros) a respeito do assunto em discussão, torna-se indispensável e altamente proveitosa a leitura de (1). 
PEREIRA, W. - A espacialização da fala no cinema. Trans/Form/Ação, São Paulo, $3: 91-103,1980$.

mico e hipostasiá-lo, como se pudesse agir por si mesmo, sem os liames com todo um conjunto de outros processos. Dessa crítica não escaparia, por exemplo, a classificação de André Malraux, que se refere aos diálogos (de cena, de tom e de exposição) de tal maneira que nos induz a pensar em atuação isolada, em pureza integral dos mesmos (11, p. 380-1). Igualmente não fugiria à crítica a divisão estabelecida por Jean Mitry, bem mais recente, em diálogo de cena (explicitando os elementos dramáticos) e de comportamento (recurso comum tanto ao cinema quanto à própria vida, uma vez que permite superar aquilo que é dito claramente e desvalar assim as significações latentes - atitudes, segundas intenções, sugestões, conotações múltiplas) (14, especialmente p. 96-100).

São páginas brilhantes de estética do cine, indubitavelmente. Mas passam longe de esgotar o veio. Pior ainda: insistem num ponto de método e de princípio absolutamente equivocado, pois isolar a fala, seja o diálogo ou qualquer outra de suas modalidades, é dar origem a um puro ente de razão. Quanto a este problema, a viragem teórica fundamental para esta disciplina que se busca a si mesma - a estética cinematográfica - , pas. sa inevitavelmente pela afirmação de duas premissas complementares: a voz humana é refundida integralmente; ela só opera em contexto de influências cruzadas e entretecidas, os recursos expressivos entrando em contato uns com os outros, lançando-se e relançando-se continuamente uns aos outros.

4. Desligando o aparelho de som. Indicamos algumas precárias classificações dos tipos de diálogos usados nos filmes. Embora repousem sobre critérios distorcidos, de pouca eficácia compreensiva e explicativa, são ainda assim bastante significativos quando os cotejamos com erros de uma outra postura infelizmente muito comum. Pensamos na atitude que consiste em marginalizar a faixa-som, ao pressupor uma relativa minimização do seu alcance. Efetivamente, escritores que se têm dedicado ao estudo do cinema parecem escrever como se vivessem ainda hoje em pleno fastígio do mudo, ou como se não estivessem de todo liberados desta tradição sem dúvida gloriosa.

A fim de melhor ilustrar essa generalizada tendência a julgar a faixa sonora de rasa importância, desdobraremos em seguida uma pequena amostragem, operando em níveis progressivamente mais reveladores e convincentes.

De início, um exemplo que poderia ser perfeitamente desculpado como lapso, deslize ou ligeira desatenção, sem qualquer relevância especial. Destaco-o de um excelente artigo, no qual se resume a perspectiva fenomenológica sobre a arte do filme. No momento em que começa a projeção, ocorreria no espectador, segudo Andrea Bonomi, uma conversão radical, pois "vejo agora apenas uma sére de imagens se desenrolarem diante dos meus olhos" ( 3 , p. 35-36). Ora, e o som? Nessa conversão radical, o sujeito-espectador ingressa apenas no reino das sombras e jamais no país dos ecos?

Aprofundemos um pouco mais. Étienne Souriau, prefaciando em 1953 uma obra coletiva de estética do cinema, assegura desde logo (muito corretamente, por sinal) que todo filme é "uma aventura bem organizada, do início ao fim". Nesse mundo autotélico, ruídos e imagens e palavras estariam diretamente referidos à diegese. A música, porém, desempenharia sobretudo uma função de atmosfera, de clima emocional. Outro traço bem característico desse universo ficcional seria, por outro lado, a curiosa psicologia dos personagens, o fato do he- 
rói "não ter sentimentos ou idéiais além daqueles que podem manifestar-se (explícita ou implicitamente) por gestos, jogos de fisionomia, movimentos; ou palavras, sempre muito breves, muito rudimentares, calculadas sempre de modo a permanecerem hierarquicamente subordinadas à aparência visual" (17, p. 26).

Uma afirmação dessas pode até mesmo passar desapercebida ao leitor menos exigente ou mais apressado. $\mathrm{Ha}-$ veria uma hierarquia a favor da imagem, u̇ma dependência da fala, que teria assim, de acordo com esta concepção, seu papel fortemente diminuído e sua carga particular de informação seriamente ameaçada. Mas, admitindo-se esta idéia, não se descobriria nunca um jeito de camuflar um dado elementar, presente em qualquer produção: a camada diegética pode emergir às vezes só no jogo verbal, outras na indissolúvel junção fala/imagem, outras ainda na fala/música ou na fala/ruído, e assim por diante. Nessa aventura bem construida - e precisamente por ser tão bem fabricada - todos os valores expressivos são integralmente acionados. As hierarquias, quando eventualmente existem, não vão muito além de meras formações provisórias, logo dissolvidas em benefício da própria dinâmica do filme.

Em terceiro lugar, e sempre penetrando mais fundo, vamos a um caso também grave e comprometedor. Em seu pioneiro esforço para estabelecer uma grande sintagmática dos filmes narrativos do período clássico, Christian Metz experimenta localizar os segmentos autônomos de Adeus Filipina, de Jasques Rozier. Dá-se, todavia, que o semiólogo se confina, por estranha opção metodológica, embora refletida e voluntária, ao recorte minucioso da faixa-imagem considerada em si mesma, extraída do contexto global.
Com este procedimento almejava detetar pelo menos um dos vários códigos que levaria à inteligibilidade do filme, "um dos capítulos de sintaxe cinematográfica".

Sua decisão metodológica, no entanto, parece-nos um falso caminho, na medida em que conduz apenas a esquemas vazios: é radicalmente impossível só manipular a sequiência de imagens, "abstração feita do elemento sonoro e falado" $(13$, p. 122). Falta-lhe qualquer existência efetiva, do ponto de vista fílmiconarrativo, desde que se pense em termos de cinema sonoro, como é o caso justamente do acervo de filmes ditos "do período clássico". E não se pode automatizá-la ou absolutizá-la, nem sequer provisoriamente, mesmo que seja para efeito operacional. O princípio peca na base, pois numa estrutura complexa (a gestalt do filme) nenhuma parte sobrevive por conta própria, de per si. Ao contrário, necessariamente as diversas instâncias se interpenetram e interagem, não tendo mais sentido uma análise que atomize o processo e depois investigue os seus componentes.

5. A fala como ocasião plástica. Estes descaminhos já nos ofereceriam muita matéria para pensar. Gostaríamos, no entanto, de finalizar este elenco de exemplos com uma verdadeira experiência-limite: um sumário levantamento crítico das visões de Galvano Della Volpe sobre aquele que seria, no seu próprio dizer, anteriormente mencionado, um "crucial problema". O filósofo italiano talvez nos possa ensinar algo definitivo, mesmo que seja pelo avesso, como ilustração do gênero de idéias e soluções que devemos evitar a todo custo.

Resenhemos, de antemão, as suas principais teses, lembrando que desta feita não se trata de uma infeliz observação de passagem (Bonomi e Souriau) ou de abs- 
PEREIRA, W. - A espacialização da fala no cinema. Trans/Form/Ação, São Paulo, $3: 91-103,1980$.

trata operação de recorte que se restringe deliberadamente a uma única dimensão cio conjunto (Metz). Inversamente, está em pauta agora uma concepção sistemática, referida inclusive a um critério estético geral, pretendendo-se sempre muito coerente nos seus passos teóricos. Sigamos então o seu raciocínio, etapa a etapa, no ítem dedicado ao cinema, em Crítica do Gosto *.

Os valores da fala aí surgem como "ocasiões plásticas", presentes de forma marcante nas películas "efetivamente realizadas", ao longo dos muitos anos de produção dos fonofilmes: As Vinhas da Ira (de John Ford), Paisà (de Rosellini), Ladrões de Bicicletas (de Zavattini e De Sica) e tantos outros. Estas plenas realizações se acham em oposição àquelas obras que se caracterizariam pela ausência de toda e qualquer força expressiva, híbridos e inconsumados pastiches fílmicoliterários, como o Hamlet de Lawrence Olivier.

Qual seria o conteúdo preciso, o avanço real, a margem de operações oferecida por esta proposta? No que consiste, afinal, a "ocasião plástica"? A formulação dellavolpiana permite-nos uma certa esperança quanto à sua capacidade de dar conta da enorme complexidade e diversidade dos meios usados no cinema, sobretudo porque ao diálogo falado é atribuida a função de exercer "um controle contínuo dos 'valores' fílmicos". Mas a esperança logo se revela infundada. $\mathrm{Na}$ da se encontra, nas exposições do grande pensador marxista, sobre as modalidades de um tal controle, os procedimentos dialéticos que deveriam proliferar nessa região de trabalho inter-semiótico. Pior ainda: o "controle" ao qual se reporta não vai além de uma "redução" da fala aos dados ópticos do campo figurativo. Decepcionantemente, em última análise pouco avançamos em relação às antecipações de um Balázs. Os efeitos verbais continuam sendo pensados como enriquecimentos e sutis complicações dos signosbase empregados nas construções das películas, ou seja, as "imagens-idéias fotodinâmicas montadas", as "imagens-símbolos dinâmico-visivas".

Neste ponto estratégico, a isso e apenas a isso se limita, bastante melancolicamente, a investigação estético-fílmica de Della Volpe, um dos mais excelentes espíritos de quantos se dedicaram à estética do cinema. O equívoco teórico que pretendíamos rastrear aflora aqui sem disfarces, elevado mesmo a categoria chave - a fala é somente um valor paralelo, um auxiliar indireto, uma "ocasião" suplementar para que as imagens em movimento se adensem e tornem-se ainda mais capazes de expressão artística. E também não se faz nenhuma referência detalhada à música ou aos ruídos, o que nos permite supô-los igualmente concebidos como elementos subordinados, a primazia cabendo sempre à "ênfase visual primária" (16).

Assim, depois de mais uma lição negativa, repitamos a observação de Godard, que nos serviu de epígrafe: ainda não se sabe ouvir e (simultaneamente) ver um

* Cf. (20), V. 6, p. 177 a 179. A tradução portuguesa, de nível bastante razoável, é mais acessível: 19 , p. 61 a 64 . Em várias passagens de outros escritos do autor a mesma idéia retorna, porque se trata de premissa básica e não de eventual imprecisão. Veja-se para uma confirmação, Il Verosimile filmico $e$ altri scritti di estetica, em 20, v. 5, p. 9 a 101 (sobretudo o ensaio "O verossímil filmico", diretamente vinculado à questão, p. 40 a 51). E também a sua intervenção na Mostra de Pesaro, já mencionada, onde repropũo a teoria da fala como "ocasião plástica". 
PEREIRA, W. - A espacialização da fala no cinema. Trans/Form/Ação, São Paulo, $3: 91-103,1980$.

filme. Só podemos lhe dar razão. Para em seguida começar a apresentar nossas indicações de pesquisa, uma tentativa de contribuir para que se supere o lamentável atraso no qual nos debatemos.

\section{Um circuito de significações. Uma} de nossas providências iniciais, páginas atrás, foi assentar com a máxima nitidez possível a radical transformação pela qual passa a fala ao ser gravada, elaborada e depois reproduzida através dos recursos técnicos. Fixamos também o fato de que se gera assim, na organização interna da obra, uma nova trama de relações entre fala, ruídos, imagens, músicas. Ao menos em larga margem ela perde então sua autonomia e já não pode mais ser identificada ou confundida com a linguagem oral de uso cotidiano. Em princípio, assume nesta conjuntura uma natureza propriamente estética, de signo que vai ser utilizado em mensagem na qual a função estética se torna primordial.

Ao que saibamos, foi Mikel Dufrenne o único teórico que vislumbrou este caráter sui generis da fala na composição cinematográfica, embora não tenha desenvolvido e explorado sua intuição. No filme, proceder-se-ia com a palavra como o affiches trabalham com os textos: "estetizando-a", obrigando-a a perder alguma coisa de sua prévia natureza lingüística. "A palavra dos atores", explica-nos Dufrenne, "faz parte da diegese; ela se dá a ouvir como a imagem a ver, mas no limite ela não é dita, entenda-se que ela não funciona como um discurso que nos seria dirigido, mas como um elemento do que nos é mostrado" (5, p. 94).

Agora, sim, estamos diante de uma pista original e segura a estetização da fala. Com efeito, no cinema a palavra falada vira espaço, a linguagem metamorfoseia-se em desenho, em arabesco, em volume. $\mathrm{O}$ filme leva-a a figurar-se, a ex- plicitar suas propriedades de ordem física, seus relevos e espessuras mais insólitos. Em correlação com as imagens (para nos limitarmos apenas a este elemento) a fala se imagifica incontinentemente, por uma espécie de exaltação recíproca. Não podemos nos limitar, por via de conseqüência, a nenhuma dependência hierárquica do verbal. Igualmente não teria sentido atribuir, sob qualquer pretexto, um primado ao elemento linguíístico. Os vínculos entre as duas séries não são nunca exteriores ou unilaterais. $\mathrm{E}$ a arte dos realizadores, da equipe que produz a obra, reside exatamente nessa habilidade para dar origem a uma tessitura na qual os fios isolados se perdem, ficam irreconhecíveis enquanto tais. Essa mesma capacidade, de resto, é a que se pressupõe no espectador ideal, qualificado: saber ouvir/ver um conjunto de reenvios significantes, um autêntico circuito de significações multidimensionais.

Por outro lado - mas é a outra face da mesma moeda, e por isso nos referimos ao poder de exaltação recíproca - o enredamento fala/imagem altera a própria natureza das fotografias. Longe de operar como fator constitutivo da representação, a título de mais um índice naturalista, como quer Marcel Martin (12, p. 174-180) a fala-em-figura provoca na verdade uma desnaturalização dos ícones. Os efeitos obtidos a partir de tão curiosa transmutações são bem conhecidos do público: estranheza, afloramento do onírico e do mítico, sugestões de poesia e de vivências surreais. Mas também efeitos de sátira, de ironia, de crítica impiedosa, como na grotesca frase de Mastroiani, em $A$ Doce Vida (de Fellini) dizendo à Diva Ekberg, de tão exagerados atributos sexuais, a baudelairiana "tu-mãe, irmã, amante". Ou, nesta mesma chave, no diplomata que se esforça por dialogar com a esposa emocionalmente transtornada, 
PEREIRA, W. - A espacialização da fala no cinema. Trans/Form/Ação, São Paulo, $3: 91-103,1980$.

em Gritos e Sussuros (de Bergman), enquanto a câmara descreve objetivamente uma formal e gélida refeição da burguesia sueca.

Tais funções precisam ser minuciosamente estudadas e, se possível, rigorosamente codificadas. Todos esses contrastes, sutis confirmações, negações extremas ou prolongamentos, toda uma gama de recursos já razoavelmente familiares aos usuários e no entanto ainda mantidos em estado de ocultamento pelos analistas do fenômeno cinematográfico. Esses procedimentos técnicos-formais, básicos tanto no recitativo lírico de Hiroshima, Meu amor (de Resnais) quanto na produção comercial mais despretenciosa, a nosso ver merecem investigação urgente e sistemática, exames concretos, filme a filme, seqüência após sequiência. E nos limitamos ao jogo fala/imagem só por comodidade expositiva. O mesmo projeto vale obviamente para os outros componentes da película - sons, gestos, ações visuais, ritmos musicais, canções, timing.

7. Nova prática significante. Antes de completar a enunciação de nossa hipótese, desbordaremos um pouco os limites do cinema para inserir o processo em questão - a imagificação da fala - em quadro mais amplo e globalizante. Este salto, na medida em que aumenta nossas bases de comparação, não nos parece extemporâneo. Se não, vejamos.

No âmbito da cultura de massa e seus media, uma prática significante, embora de história recente, vai se definindo de modo acelerado, bem diante de nossos olhos: a iconização, em grau crescente, da linguagem. Sem a menor hesitação possível, refletir sobre a fala no cine leva em primeira instância a uma retomada pela raíz desta nova 1 dática semiótica, que ainda está aguardando uma descrição integral das suas experiências e resultados*.

Enfocando-a sob o ângulo da escrita talvez seja mais praticável oferecer dela uma noção sumária. Leve-se em conta, por exemplo, a tematização das unidades da escrita nos mais variados domínios que hoje nos solicitam - revistas em quadrinhos, sinalética, painéis didáticos, jornais, revistas, cartazes com "suas letras maiores do que torres". Na civilização urbana e industrial, sob muitos aspectos a própria cidade, com suas publicidades e anúncios luminosos, assemelha-se a um gigantesco texto. "O mais belo espetáculo in the world não foi realizado por um artista", diz Fernand Léger sobre Nova Iorque, cuja beleza à noite seria "formada por esses numerosos pontos luminosos e pelo jogo infinito da publicidade móvel" (10, p.187).

Podemos, no entanto, ir mais adiante. Todos os gêneros artísticos, mesmo os mais tradicionais e aparentemente estabilizados, estão em parte voltados para a crescente figuração da linguagem. Recordemos aqui, a título de comprovação, a participação essencial das ilustrações nas últimas novelas de Cortazar, as experimentações com caracteres tipográficos e signos visuais no Compact de Maurice Roche, as técnicas dos gibis no Poema a Fumetti de Buzzati. Ou ainda, mais próximos e mais familiares, no setor da nossa poesia de vanguarda, os trabalhos com a visualização das letras e dos blocos de palavras nos poemas concretos ou nos poemas-processos. E nas artes visuais, por seu turno, fazendo explodir a viciosa separação entre os meios figurativos e verbais, aí estão as frases nas pinturas de Indiana, desenhos de Adão Pinheiro com seus

\footnotetext{
* (Vamos estabelecer algumas linhas-mestras para uma tal descrição.)
} 
alfabetos pessoais, grandes letras de matéria plástica transparente nas esculturaspalavras de Gerchman, cartazes nas manifestações conceituais, tantas e tantas outras aventuras igualmente reveladoras.

No interior desse rico e multifacetado contexto civilizacional é que devemos compreender e interpretar a espacialização da linguagem no cinema e, por extensão, se nos permitem a abrupta passagem, inclusive na televisão. A nosso ver se trata, evidentemente, de uma profundíssima alteração nas próximas maneiras de transmitir e criar informações, tanto as de imediata função utilitária quanto as de propósitos estéticos bem definidos.

Compartilhando deste clima, intencionalmente ou sem dar-se conta, os fruidores começam a aprender e a exercitar uma insólita atitude perceptivo-racional: ver/ler/ouvir em totalidade. Deste modo, somos os "primitivos de uma nova era" (para usar de novo uma metáfora oswaldiana), pois o olhouvido só existe, por enquanto, no estado selvagem. E o cine, por vocação peculiar e por afinidade nascida da contemporaneidade, estimula precisamente esse órgão cujo nascimento estamos de certa maneira diagnosticando.

8. Conclusão provisória. Fazendo um retorno ao problema central, podemos finalmente arrematar a colocação de nossa hipótese. Parece-nos já suficientemente indicado que a fala ingressa, no filme narrativo, em síntese orgânica que entretece as mais variaaas espécies de signos. Essa talvez seja, por sinal, a mais importante significação do próprio cinema como $m e^{-}$ dium, a insubstituível experiência que nos proporciona: dialeticamente apresentar e logo em seguida desconstituir os materiais, compô-los e desmontá-los em cima,numa dinâmica sucessão de elementos, diversificados originariamente mas logo assimilados graças à energia unificadora do filme. Não residiria aqui, bem precisamente, a natureza essencial da película, sua realidade última e seu mais notável campo de estimulação?

Dentro desse quadro teórico fica mais plausível a elucidação do papel da fala. Entre o começo da filmagem (ou mesmo antes, muito antes, desde as primeiras tentativas de concretizar-se no imaginário o roteiro previsto) e a recepção do trabalho final, agem os processos de tran sição, que absorvem os dados particularizados. Encarregam-se de homogeneizálos, no seio da nova totalidade, as câmaras, gravadores, mixagens, montagens de som e de imagens, intervenções físicoquímicas sobre as películas, amplificadores, produtores de ruídos artificiais, caixas acústicas e muitas outras técnicas especializadas.

Cabe-lhes, então, o recolhimento, a depuração, a combinatória, a unificação e projeção terminal da singular fonte de significações. Não há que estabelecer, portanto, a precedência de um sistema sobre o outro. Não são pura e simplesmente transpostos para o universo do filme, como se ainda fossem os mesmos sistemas da realidade pré-cinematográfica. E também não vem mais ao caso dissertar sobre um deles, tomado em si, pois não seria do tecido fílmico que se estaria cuidando.

Infere-se assim, de forma lógica e natural, contra a posição de Della Volpe e outros, que não há realmente uma linguagem específica do cinema, desde que se a pense como hierarquias e dependências internas, quer seja a favor do visual ou de qualquer outra dimensão. Tudo o que foi exposto acima nos conduz também a negar que a película não passe de uma reunião heteróclita de códigos. Uma concepção deste gênero está assentada numa visão deformada do próprio objeto de reflexão, que não é jamais 
um ser compósito ou misto. * Antes pelo contrário, há nele um traço particularíssimo, irredutível e extremamente complexo, que faz com que se trate precisamente de um filme e não de uma lanterna mágica, ou uma sucessão de slides, ou de uma história em quadrinhos, ou de um álbum fartamente ilustrado: a homogeneização das eventuais unidades integradas, dissolvendo-as e transfigurando-as, desmontando-as para melhor incorporálas ao fluxo terminal, este sim o único "específico fílmico" a ser constantemente reafirmado.

$\mathrm{Na}$ terminologia de Hjelmslev, a própria substância da expressão que as formas estruturam e organizam já é no caso do filme um todo inscindível, resultado de um peculiar trabalho semiótico. $\mathrm{O}$ diversificado e heteróclito é a matéria pré-fílmica. Não poderia haver tanta confusão a respeito destes planos: sons, imagens, diálogos, gestos, cenários, roupas são transcendidos e unificados em substância só encontrável no cinema. Não está no real, nem no roteiro, nem no copião, nem mesmo nos fragmentos a serem montados. Vai além de todas estas etapas, embora as perpasse todas. E um objeto inédito, o filme exatamente. Em boa verdade, nada mais e nada menos do que um filme, desde o primeiro instante, no nível da substância manipulada. Isto é que se precisaria ter em conta, até as últimas consequiências.
Diante de nós há portanto uma pesquisa minuciosa a ser desenvolvida. Um sem-número de análises concretas de textos fílmicos deverão ser executadas. Em que medida o valor de uma obra está na dependência dessa completa fusão dos elementos heterogêneos? Como se dá, na prática, a absorção de materiais de origens tão híbridas e tão diversificadas? Não é sumamente paradoxal esta reflexão sobre o papel da fala, que acaba por desembocar na radical negação de sua autono. mia? Ficam enunciadas as perguntas, uma vez que, devido à completa ausência de investigações dessa ordem, preferimos mover-nos em instância modesta e preliminar. Pecamos até por um excesso de generalização e de abstração. Mas nos daríamos por satisfeitos se, pelo menos, chamássemos a atenção para a necessidade de estudar as questões com maior empenho. Vale também para este objeto de conhecimento a licão de Sigmund Freud: "as teorias complefas não caem do céu, e com toda a razão vocês desconfiarão se alguém lhes apresentar, logo de início de suas observações, uma teoria sem falhas, otimamente rematada. Tal teoria certamente só poderá ser filha de uma especulação e nunca o fruto da pesquisa imparcial e sem prevenções da realidade" (7, p. 22).

A tempo: talvez fosse indispensável uma seção dedicada apenas à introdução do silêncio, que veio complicar ainda mais o jogo de reenvios significantes. "O cinema sonoro inventou sobretudo o silência". Bresson.

* Cf. a respeito (8) especialmente o cap. 2, "Teoria del film sonoro e l'eterogeneità del linguaggio cinematográfico", p. 47 a 99. Polemiza-se aí, brilhante e documentadamente, sobretudo com Rudolf Arnheim, autor cujas idéias só deixamos de enfatizar aqui por mero acaso. Corrigimos a falha através desta nota, que rende homenagem ao rigor e ao pioneirismo do ensaísta de "Novo Laocoonte", ponto de referê cia obrigatório para todos os que desejam analisar os problemas da estética cinematográfica (e inclusive o papel da fala no interior do filme). 
PEREIRA, W. - A espacialização da fala no cinema. Trans/Form/Ação, São Paulo, $3: 91-103,1980$.

TRANS/FORM/AÇĀO/24

PEREIRA, W. - The spatialization of speech in the cinema. Trans/Form/Ação, São Paulo, $3: 91-103,1980$.

SUMMARY: It is rather unsatisfactory at the current phase of research the way in which the relations between images and words in the film universe are discussed. This is nevertheless a crucial issue regarding the aesthetics of the cinema. Most of the analyses carried out emphasize only the role of the imagens in the genesis and development of the significations. The working hypothesis set forth here has a different proposition, that is, an approach to the sign complex formed by the indissoluble fusion of both expressive resources, which is to be viewed as an specific, original and absolutely new means of communication. This quite new character calls for a detailed and urgent research in which philosophical, semiotic and properly cinematographical approaches are brought together.

UNITERMS : Aesthetics ; semiotics ; cinema ; film ; speech ; discourse ; iconization, imagification and logos_iconic.

\section{REFERENCIAS BIBLIOGRÁFICAS}

1. ARISTARCO, Guido. História das teorias do cinema. Trad. Maria Helena Sacadura e Júlio Sacadura. Lisboa, Arcádia, 1961.

2. BAZIN, René. Qu'est-ce que le cinéma? Paris, Du Cerf, 1958, V. 1.

3. BONOMI, Andrea. Filme, realidade e linguagem: perspectiva fenomenológica. Tempo bras. $3(7): 33-44$, out. 1965.

4. CÂMARA JUNIOR, J. Mattoso. Dicionário de filologia e gramática. 3. ed. Rio de Janeiro, J. Ozon, 1968. 383 p.

5. DUFRENNE, Mikel. Estética et philosophie. Paris, Klincksieck, 1967.

6. EISENSTEIN, Sergei. Da revoluçã® à arte, da arte à revolução. Trad. e sel. de textos por C. Braga e I. Canelas. Lisboa, Presença, s.d.

7. FREUD, Sigmund. Cinco lições de psicanálise. Trad. Durval Marcondes. Rio de Janeiro, Imago, 1970. V. 11.

8. GARRONI, Emílio. Semiótica ed estética. Bari, Laterza, 1968.
9. JEANNE, René \& FORD, Charles. His toire illustré du cinéma. Paris, Marabout, 1966, v. 2.

10. LEGER, Fernand. Fonctions de la peinture. Paris, Gonthier, 1965.

11. MALRAUX, André. Esquisse d'une psychologie du cinéma. In: L'HERBIER. Mercel, ed. L'intelligence du cinematographee. Paris, Correa, 1945.

12. MARTIN. Marcel. Le langage $d u$ cinéma. Paris, Du Cerf., 1968.

13. METZ, Christian. Analyse sintagmatique de la bande-image. In: Essais sur la signification au cinéma. Paris, Klincksieck, 1968.

14. MITRY, Jean. Esthétique et psychologie du cinéma. Paris, Ed. Universitaires, 1965. v. 2 .

15. MOUNIN, Georges. Introduction à ia semiologie. Paris, Minuit, 1970. 
PEREIRA, W. - A espacialização da fala no cinema. Trans/Form/Ação, São Paulo, 3:91-103, 1980.

16. PEREIRA, Wilcon. Escritema e figuralidade. Assis, Faculdade de Filosofia, 1975. [Tese - Doutoramento].

17. SOURIAU, Étienne. Les grands caractères de l'univers filmique. In: L'univers filmique. Paris, Flammarion, 1953, p. 11-31.
18. STEPHENSON, Ralph \& DEBRIX, J. R. $O$ cinema como arte. Trad. Tati de Moraes. Rio de Janeiro, Zahar, 1969.

19. VOLPE, Galvano Della. Crítica do gosto. Trad. Antonio Ribeiro. Lisboa, Presença, s.d., v. 2.

20. 1973. 